\title{
Insufficient Vitamin D Intake and Low Vitamin D Status in Men Over 80 Y of Age: Intervention is Required to Meet Dietary Targets in Long-Term Care Facilities
}

\author{
Isabelle Germain ${ }^{1,2}$, Sherry Agellon ${ }^{1}$ and Hope Weiler ${ }^{1 *}$ \\ ${ }^{1}$ School of Dietetics and Human Nutrition, McGill University, Ste Anne de Bellevue, Canada \\ 2Ste-Anne's Hospital, Veterans Affairs Canada, Ste-Anne de Bellevue, Canada
}

\begin{abstract}
Description: Vitamin $D$ is important to bone health. This study examined vitamin $D$ intake and status in institutionalized elderly men in relation to biomarkers of bone metabolism and functional indicators.

Materials and Methods: Elderly male veterans were studied in Phase I $(n=40)$ for 16 weeks (April, June, August 2008) and Phase II $(n=30)$ for another 16 weeks (October and December 2008 and February 2009) for dietary vitamin D using 5 day menu selection (Phase I) and using $3 \times 3-d$ weighed food records (Phase II). Anthropometric data, Mini-Mental State Evaluation (MMSE) scores and sun exposure were collected. Functional capacity was assessed using the Frail Elderly Functional Assessment Tool (FEFA) and handgrip strength. Biochemistry included serum 25-hydroxyvitamin D (25(OH)D), parathyroid hormone (PTH), osteocalcin (OC) and C-terminal telopeptides of Type 1 collagen (CTX). Mixed model ANOVA and Pearson correlation analyses were used.

Results: Participants were relatively healthy (Age: $85 \pm 3$ years (Mean \pm SD), BMI: $26.1 \pm 4.3 \mathrm{~kg} / \mathrm{m}^{2}$, MMSE: 25 \pm 5 , FEFA: $13 \pm 8$, grip strength: $22 \pm 8 \mathrm{~kg})$. Sixty-six percent $(280 \pm 120 \mathrm{lU})$ of the planned dietary vitamin $\mathrm{D}$ was consumed. Vitamin D came mainly from fortified milk and meal supplements and $33 \%$ took pill supplements $(400-800$ $\mathrm{IU} / \mathrm{d}$ ). Serum 25(OH)D concentration rose by summer (Phase I: $60.9 \pm 24.4,68.2 \pm 24.6$ and $76.1 \pm 22.4 \mathrm{nmol} / \mathrm{L}$, respectively) and declined thereafter (Phase II: $57.7 \pm 24.1,62.9 \pm 30.7$ and $61.3 \pm 29.2 \mathrm{nmol} / \mathrm{L}$ ). PTH was lower in spring compared to late summer through winter whereas CTX and OC did not change. Serum $25(\mathrm{OH}) \mathrm{D}$ was correlated to BMI, but not to indicators of functional status.
\end{abstract}

Conclusions: In long-term care, vitamin D from foods and supplements fails to meet recommendations of $800 \mathrm{IU}$ $(20 \mu \mathrm{g})$ for those over $70 \mathrm{y}$.

Keywords: Vitamin D intake; 25-hydroxyvitamin D; Men; Longterm care

\section{Introduction}

Aging is associated with reduced bone health, reduced mobility and increased need for help in accomplishing activities of daily living [1]. Vitamin D is considered an important nutrient for its role in bone health with well known consequences of deficiency leading to osteomalacia and osteoporosis in the elderly [2]. It is predicted that in 2025 , more than $20 \%$ of Canadians will be over the age of 65 y [1]. These statistics are very similar to other countries. For example, by $2040,21 \%$ of the population will be aged 65 years or older in the United States [3] and will represent $36.1 \%$ of the population in Japan [4].

For most people, values of 25-hydroxyvitamin D (25(OH)D) above $50 \mathrm{nmol} / \mathrm{L}$ are sufficient to maintain bone health [5]. However, low vitamin $\mathrm{D}$ status demarked by circulating $25(\mathrm{OH}) \mathrm{D}$ below $50 \mathrm{nmol} / \mathrm{L}$ has been reported in community dwelling [6-9] and institutionalized elderly [10-12]. In the community, a wide range of values have been reported. A large cohort study looking at bone health in American men reported blood levels of $25(\mathrm{OH}) \mathrm{D}$ to be $62.5 \pm 19.8 \mathrm{nmol} / \mathrm{L}$ with $2.9 \%$ below the deficiency cut-off of $30 \mathrm{nmol} / \mathrm{L}$ [13]. The Canadian Health Measures Survey reported that men over the age of 70 years presented with $25(\mathrm{OH}) \mathrm{D}$ values of $71 \pm 27.5 \mathrm{nmol} / \mathrm{L}$ with $10 \%$ of them below 37.5 $\mathrm{nmol} / \mathrm{L}$ [14]. More recently, elderly men living in the community in Australia were reported to have levels of $25(\mathrm{OH}) \mathrm{D}$ as low as $42 \mathrm{nmol} / \mathrm{L}$ [15]. Less is known about those in institutions. In long-term care facilities where 25(OH)D was assessed, values ranging from 26 to 40 $\mathrm{nmol} / \mathrm{L}$ were seen despite a supervised environment. Low status may be ascribed to vitamin D intakes below recommendations [10,11,16-20], in some cases as low as $120 \mathrm{IU} / \mathrm{d}$. Such intakes are exceptionally low in view of the newly updated recommendations by Institute of Medicine
(IOM) Dietary Reference Intakes (DRI) for Calcium and Vitamin D [5]. The IOM modified the recommendation from an Adequate Intake (AI) to now include Estimated Average Requirements (EAR) and Recommended Dietary Allowances (RDA). For adults of $>70$ years, a daily EAR of $400 \mathrm{IU}(10 \mu \mathrm{g})$ and RDA of $800 \mathrm{IU}(20 \mu \mathrm{g})$ were set in comparison to the previous AI of $600 \mathrm{IU}(15 \mu \mathrm{g})$.

Vitamin D intake and serum 25(OH)D levels have been reported to be both below dietary and status targets in institutionalized elderly populations of women and men. This deserves further attention since better 25(OH)D status has been associated with better leg strength and function [21], grip strength [22], general physical activity and daily living activity $[23,24]$. Furthermore, low serum concentration of $25(\mathrm{OH}) \mathrm{D}$ has been identified as a risk factor for long-term care facility admission [25]. Moreover, bone turnover is a constant physiological phenomenon and although aging is associated with higher resorption than formation, vitamin $\mathrm{D}$ should be provided in sufficient amounts to ensure normal parathyroid hormone (PTH) concentrations and reduce associated morbidity and mortality risks $[26,27]$. Nonetheless,

${ }^{*}$ Corresponding author: Hope Weiler, School of Dietetics and Human Nutrition, McGill University, Canada, E-mail: hope.weiler@mcgill.ca

Received June 10, 2013; Accepted June 12, 2013; Published July 17, 2013

Citation: Germain I, Agellon S, Weiler H (2013) Insufficient Vitamin D Intake and Low Vitamin D Status in Men Over 80 Y of Age: Intervention is Required To Meet Dietary Targets in Long-Term Care Facilities. Vitam Miner 2: 113.

Copyright: @ 2013 Germain I, et al. This is an open-access article distributed under the terms of the Creative Commons Attribution License, which permits unrestricted use, distribution, and reproduction in any medium, provided the original author and source are credited. 
information specifically regarding very old males (aged $80+$ ) is scarce and impacts on biomarkers of bone metabolism are not as well studied.

The primary objective of this 1 year prospective cohort study was to evaluate vitamin D intake and $25(\mathrm{OH}) \mathrm{D}$ concentrations in a longterm care population of elderly male veterans (aged $80+\mathrm{y}$ ) across all seasons. Our secondary objective was to track changes in biomarkers of bone metabolism including PTH, osteocalcin (OC) and C-terminal telopeptides of Type 1 collagen (CTX) over the year as well as changes in Frail Elderly Functional Assessment (FEFA) and the Mini-mental State (MMSE) tool scores in association with vitamin D status. It was hypothesized that all participants would present with low serum $25(\mathrm{OH}) \mathrm{D}(<50 \mathrm{nmol} / \mathrm{L})$ regardless of sampling time, that total intake of vitamin $\mathrm{D}$ would be below recommendations and that $25(\mathrm{OH}) \mathrm{D}$ concentration would be significantly related to functional tests of daily living.

\section{Materials and Methods}

This prospective observational cohort study was conducted in elderly males living at Ste. Anne's Hospital, a long-term care facility (Veterans Affairs Canada, Montreal, QC; $46^{\circ} \mathrm{N}$ ). Phase I took place from spring to summer ( 16 weeks; $n=40$ ) whereas Phase II captured the fall to winter period ( 16 weeks) for 30 of the 40 original participants. Of the 10 participants who did not continue in Phase II, 4 died, 3 had a significant cognitive decline and the other 3 did not wish to participate. In view of the study objectives, all veterans over the age of 70 years were eligible including those with stable chronic diseases, receiving oral and enteral feeding modes. There were 8 exclusion criteria: 1 ) endstage (i.e., prognosis of less than 4 months) conditions and palliative care, 2) end-stage renal disease due to altered vitamin D metabolism, 3) use of vitamin D analogues, 4) end-stage liver disease, 5) untreated hyperparathyroidism, 6) active cancers, 7) metabolic bone diseases except for osteoporosis and osteomalacia and, 8) any acute condition that would exclude any oral intake of food. The completion of the 3 month study phase or, change in clinical status preventing continuance in the study was considered the end-point (Figure 1). The study was approved by the Institutional Review Board of the Faculty of Medicine of McGill University and Ste. Anne's Hospital Scientific Board. Consent forms stated voluntary participation, right to withdraw at any time without consequences and respect of privacy. Competency to consent was validated via medical records or confirmed with the treating physician. When competent, the patient signed the consent form for himself. If participant was unfit to consent, the legal representative (mandatory, curator or tutor) signed, as per required by Article 21 of Quebec Civil Code.

Participants were measured for weight using a standard balance, calibrated yearly at the hospital. Height was obtained from the military medical chart and confirmed using knee-height measuring calliper (Seca 207 model, Seca Corp, MD, US) using algorithms adjusted for age and sex calculations, then body mass index $\left(\mathrm{BMI} ; \mathrm{kg} / \mathrm{m}^{2}\right)$ was calculated. A nurse met with participants to complete a MMSE at baseline (unless the medical chart had a MMSE score dated less than 3 months prior to the study) and at the end of each phase of the study. The FEFA scores were obtained at midway and final assessments. Handgrip strength (Hydraulic hand dynamometer, Jamar') was performed at midway and final assessments of Phase II (Fall-Winter). Subjects were instructed to squeeze the handle as hard as they could and were encouraged for 20 second each trial. The maximum reading of each trial was recorded. Measurements were done in triplicates, using the non dominant arm and average values were used. The time used to read and record the data (approximately $15 \mathrm{sec}$.) was used as a rest period.
In both segments of the study, fasted blood samples were obtained every 8 weeks, between 0630 and 0730 h. Routine biochemistry were immediately measured at the hospital using Vitros 250E (Ortho Clinical Diagnostics, Johnson \& Johnson, version 250) and Symex XT-2000i (Sysmex, version XT-2000i/XT-1880i) auto analyzers. This laboratory participates in the ISO (Norm 15189-Medical Laboratories) quality assurance program. Sample aliquots were stored at $-80^{\circ} \mathrm{C}$ until further testing at McGill. Serum total 25(OH)D, PTH, OC was measured using chemiluminescent immunoassays (Liaison; DiaSorin, Minnesota) and serum CTX by colorimetric immunoassay (IDS Inc, Arizona). This laboratory participates in the DEQAS (Vitamin D External Quality Assessment Scheme) program and consistently reports results within $25 \%$ of the ALTM (All-Laboratory Trimmed Mean). Controls were in range with specifications of each assay. Intra-assay variability ranges were $0.1 \%-8.1 \%$ for $25(\mathrm{OH}) \mathrm{D}, 0.18 \%-12.4 \%$ for $\mathrm{PTH}, 0 \%-5.8 \%$ for OC and $0 \%-14.8 \%$ for CTX. Inter-assay variability ranges were $5.3 \%-15.8 \%$ for $25(\mathrm{OH}) \mathrm{D}, 1 \%-7.7 \%$ for PTH and $1.8 \%-7.3 \%$ for OC.

Main food sources of vitamin D were examined in Phase I using 5 days of hospital menus at each time point, for all participants. In Phase II, actual food intake was assessed using weighed food records for 3 non consecutive days, including a weekend day, in October, December and February. All foods were weighed before being served and leftover weights were deducted to obtain actual intake. For Phase II, a database including all detailed recipes cooked in the Production Center of the Hospital was used to determine nutritional composition. The Canadian Nutrient File 2007b and menu management software ProMenu was used to generate nutrient intakes to reflect the period of study. Nutritional values of market foods were included to complete the missing nutritional values of certain items. Intakes were compared to the various DRI values.

\section{Statistical analyses}

Continuous variables were expressed as means \pm SD or median (range), if non-normally distributed. Categorical variables were expressed as $n$ (\%). All data were checked for normality using D’Agostino \& Pearson omnibus normality test; when normality criteria were not met, data were log transformed or a nonparametric test was used. Levene's test was used to determine homogeneity of variances. The relationships among time and vitamin D intake with $25(\mathrm{OH})$

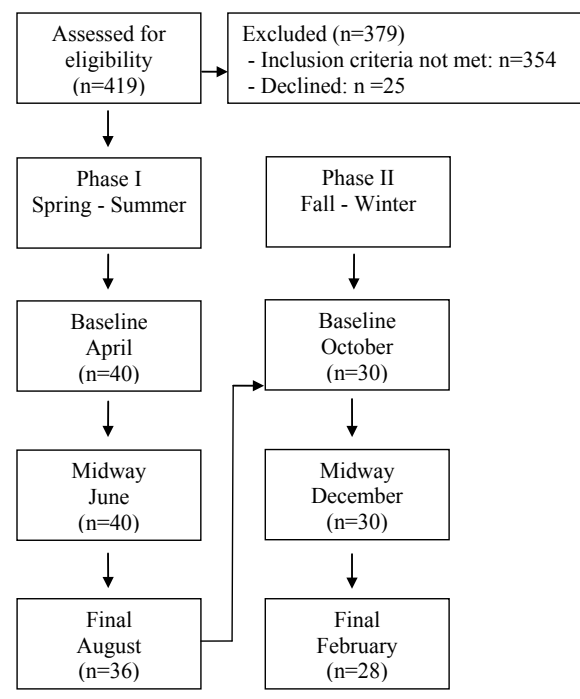

Figure 1: Recruitment for Phase I and Phase II. 
Citation: Germain I, Agellon S, Weiler H (2013) Insufficient Vitamin D Intake and Low Vitamin D Status in Men Over 80 Y of Age: Intervention is Required To Meet Dietary Targets in Long-Term Care Facilities. Vitam Miner 2: 113.

Page 3 of 7

D, PTH, OC and CTX were assessed using a mixed model ANOVA, controlling for random effect of age. Tukey-Kramer was used as post hoc test. Relationships between $25(\mathrm{OH}) \mathrm{D}$ and other measures were tested using Pearson correlation analyses. Statistical significance was set at $p \leq 0.05$, and all $p$ values presented are 2 tailed. Data were analyzed using Statistical Analysis System, version 9.2, statistical software (SAS Institute Inc., Cary, N.C.).

\section{Results}

In general, the participants were of healthy body weight for age, in good mental status and had routine serum biochemistry within the normal range (Tables 1 and 2). Thirty-three percent of participants were receiving a supplement containing vitamin $\mathrm{D}(\mathrm{n}=6$ received 400 $\mathrm{IU} / \mathrm{d}, \mathrm{n}=2$ received $600 \mathrm{IU} / \mathrm{d}$ and $\mathrm{n}=2$ received $800 \mathrm{IU} / \mathrm{d}$ ). Sunlight exposure was minimal for most participants due to limited outdoor activities or because hats, long sleeves and pants were worn regularly. From April to August, 73\% (29) of participants were able to go outside for an average period of $41 \mathrm{~min}$ per day (Range: $2-180 \mathrm{~min} / \mathrm{d}$ ). Thirteen participants were less than $15 \mathrm{~min}$. outdoors every day. Eighty percent (80\%) wore hats, $53 \%$ wore long sleeves and $75 \%$ wore long pants. Although ultraviolet beta (UVB) radiation is minimal in the fall to winter months, sunlight exposure was observed. During that period, only $21.4 \%$ participants went outdoors, and all of them wore hats, long sleeves and long pants.

In Phase I, the analysis of the foods identified as the main sources of vitamin D provided on the hospital tray (average of $3 \times 5$ days of proposed menus) revealed a mean dietary vitamin D of $240 \pm 160 \mathrm{IU} / \mathrm{d}$. In Phase II, the nutrient intake was obtained via average weight of all foods of 9 days of intake ( 3 days at baseline, 3 days at midway and 3 days at final assessments) using detailed recipes. No difference was seen among days, therefore the mean of 9 days of intake was used (Table 3). The diet was well balanced for macronutrients. The vitamin D content of all foods served was $440 \pm 200 \mathrm{IU} / \mathrm{d}$, however, only $66 \%$ of that was consumed. At the time of the study, the recommendation for vitamin $\mathrm{D}$ was an AI set at $600 \mathrm{IU}$ revealing that the assessed menu could not met these recommendations with food and meal supplements alone. In Phase II, actual intakes were compared to DRI values; only 1 participant (3\%) exceeded the AI of $600 \mathrm{IU}$ with food and meal supplements alone in October, December and February. Similarly, when comparing to the 2011 revised DRIs, only 1 participant $(3 \%)$ reached the new 800 IU/d RDA value with food alone (February only). Three participants (10\%) met the EAR of $400 \mathrm{IU}$ in October and December whereas 4 participants (14\%) met the EAR in February with food and meal supplements alone. The main sources of dietary vitamin D (52\%) were fortified milk, enriched meal supplements and milk-based soups and margarine.

\begin{tabular}{|c|c|c|c|c|}
\hline & \multicolumn{2}{|c|}{ Phase I $(n=40)$} & \multicolumn{2}{|c|}{ Phase II $(n=30)$} \\
\hline & Mean* & SD & Mean* & SD \\
\hline Age, y & 85.2 & 3.2 & 84.9 & 3.6 \\
\hline Weight, kg & 76.0 & 12.7 & 74.7 & 13.2 \\
\hline $\mathrm{BMI}, \mathrm{kg} / \mathrm{m}^{2}$ & 26.1 & 4.1 & 26.0 & 4.3 \\
\hline MMSE (/30) & 23.0 & 7.0 & 24.0 & 3.0 \\
\hline FEFA (/55) & 13.0 & 8.0 & 13.0 & 8.0 \\
\hline Number of prescriptions ${ }^{\star *}$ & 11.0 & 5.0 & 11.0 & 5.0 \\
\hline Handgrip (kg) & \multicolumn{2}{|c|}{ N/A } & 10.0 & 3.6 \\
\hline
\end{tabular}

*Stable over time, within phases.

**Including vitamin tablet supplements.

FEFA: Frail Elderly Functional Assessment; MMSE: Mini Mental State Evaluation; N/A: not assessed.

Table 1: Characteristics of participants (Mean \pm standard deviation).

\begin{tabular}{|c|c|c|c|c|c|}
\hline & Normal Range $^{1}$ & \multicolumn{2}{|c|}{$\begin{array}{c}\text { Phase I } \\
(\mathrm{n}=40)\end{array}$} & \multicolumn{2}{|c|}{$\begin{array}{c}\text { Phase II } \\
(\mathrm{n}=30)\end{array}$} \\
\hline & & Mean $^{*}$ & SD & Mean $^{*}$ & SD \\
\hline Glucose (nmol/L) & $4.1-5.9$ & 5.2 & 1.1 & 5.2 & 0.9 \\
\hline Albumin (g/L) & $35-50$ & 35 & 4 & 36 & 4 \\
\hline Phosphate $(\mathrm{mmol} / \mathrm{L})$ & $0.81-1.45$ & 1.14 & 0.17 & 1.20 & 0.16 \\
\hline Total calcium (mmol/L) & $2.10-2.55$ & 2.27 & 0.09 & 2.23 & 0.08 \\
\hline lonized calcium (mmol/L) & $0.95-1.15$ & 1.04 & 0.05 & 1.03 & 0.04 \\
\hline Total cholesterol (mmol/L)** & $0-6.2$ & 4.1 & 0.9 & 4.3 & 0.8 \\
\hline Triglycerides (mmol/L) & $0-2.26$ & 1.58 & 0.70 & 1.59 & 0.81 \\
\hline
\end{tabular}

${ }^{1}$ References values of Ste-Anne's Hospital Laboratory.

*Stable over time, within each phase:

**Total cholesterol and Triglycerides were only obtained at baseline and final assessments in Phase I and in Phase II.

Table 2: Serum biochemistry of participants.

\begin{tabular}{|c|c|c|c|c|c|}
\hline Intake per day & DRI $^{1}$ & \multicolumn{2}{|c|}{ Provided on Tray } & \multicolumn{2}{|c|}{ Consumed } \\
\hline & & Mean & SD & Mean & SD \\
\hline Energy, kcal & $3067^{2}$ & 2522 & 547 & 1744 & 351 \\
\hline Protein, g (\%Energy) & $56(10-35 \%)$ & 102 & $23(16 \%)$ & 69 & $16(15 \%)$ \\
\hline CHO, g (\%Energy) & $130(45-65 \%)$ & 333 & $76(51 \%)$ & 233 & $56(51 \%)$ \\
\hline Fiber, g & 30 g $^{*}$ & 22 & 8 & 14 & 6 \\
\hline Fat, g (\%Energy) & $---(20-35 \%)$ & 90 & $24(31 \%)$ & 62 & $15(31 \%)$ \\
\hline Vitamin D, IU & $800 \mathrm{IU}^{3}$ & 440 & 200 & 280 & 120 \\
\hline Calcium, mg & $1200 \mathrm{mg}^{3}$ & 1488 & 632 & 1013 & 424 \\
\hline Phosphorus, mg & $700 \mathrm{mg}^{*}$ & 1837 & 569 & 1255 & 376 \\
\hline Sodium, mg & $1200 \mathrm{mg}^{*}$ & 3936 & 939 & 2512 & 653 \\
\hline Potassium, $\mathrm{mg}$ & $4700 \mathrm{mg}^{*}$ & 4010 & 969 & 2643 & 736 \\
\hline
\end{tabular}

${ }^{1}$ Values are RDA; when followed by $\left(^{*}\right)$ values represent Adequate Intake (AI).

${ }^{2}$ Estimated Energy Requirement (EER): For males, subtract $10 \mathrm{kcal} / \mathrm{d}$ for each year above 19 .

${ }^{3}$ New DRI values (IOM, 2011): RDA: Vitamin D, 800 IU and Calcium, 1200 mg EAR: Vitamin D, $400 \mathrm{IU}$ and Calcium, $1000 \mathrm{mg}$.

${ }^{4}$ Does not include pill supplement.

Table 3: Average daily intake in elderly living in long-term care facility (Phase II - 9 days; Mean \pm SD)

In Phase II, only 33\% of participants were receiving vitamin $\mathrm{D}$ from tablets to enhance their exogenous intake, providing an average additional $530 \pm 160 \mathrm{IU} / \mathrm{d}$. Pill supplement dosages ranged from $400 \mathrm{IU} / \mathrm{d}$ to $800 \mathrm{IU} / \mathrm{d}$. When considering actual food-derived vitamin $\mathrm{D}$ intakes and the additional intake of vitamin $\mathrm{D}$ from pill supplementation, $27 \%(8 / 30)$ of participants met the AI of $600 \mathrm{IU} / \mathrm{d}$ in October and December whereas 24\% (7/29) met the AI in February. With the revised IOM values, $40 \%(12 / 30)$ of participants met the EAR value at every time point. The RDA was met by13\% (4/30) of participants and by $10 \%(3 / 30)$ in October and February.

In Phase I of this prospective study, mean serum 25(OH)D concentrations were above $50 \mathrm{nmol} / \mathrm{L}$ in April, June and August (Table 4) for this elderly institutionalized population. The proportion of participants presenting with $25(\mathrm{OH}) \mathrm{D}$ concentrations above 50 $\mathrm{nmol} / \mathrm{L}$ increased from $72.5 \%$ in April to $77.5 \%$ in June and $88.9 \%$ in August. In April, $10 \%$ of the participants were deficient $(<30 \mathrm{nmol} / \mathrm{L})$. However, in June and August no participant was deficient (Figure 2). In Phase II, the proportions of participants presenting with $25(\mathrm{OH})$ D concentrations above $50 \mathrm{nmol} / \mathrm{L}$ were $60.0 \%$ in October, $65.5 \%$ in December and $67.9 \%$ in February. Deficiency was observed in $10.0 \%, 10.3 \%$ and $17.9 \%$ of the population in October, December and February, respectively.

Biomarkers of bone metabolism over a year are shown in Table 4. In the months of April, June and August, mean 25(OH)D, PTH and OC concentrations were within their respective normal ranges. During the fall to winter segment of the study PTH levels were 
Citation: Germain I, Agellon S, Weiler H (2013) Insufficient Vitamin D Intake and Low Vitamin D Status in Men Over 80 Y of Age: Intervention is Required To Meet Dietary Targets in Long-Term Care Facilities. Vitam Miner 2: 113.

Page 4 of 7

\begin{tabular}{|c|c|c|c|c|c|c|c|c|c|c|}
\hline & \multicolumn{2}{|c|}{ Normal Range } & \multicolumn{2}{|c|}{ Serum $25(\mathrm{OH}) \mathrm{D}^{*}(>50 \mathrm{nmol} / \mathrm{L})$} & \multicolumn{2}{|c|}{ Serum 1-84 PTH (1.1 - $7.5 \mathrm{pmol} / \mathrm{L})$} & \multicolumn{2}{|c|}{ Serum OC $(2.4-7.9 \mathrm{nmol} / \mathrm{L})$} & \multicolumn{2}{|c|}{ Serum CTX (ng/L) } \\
\hline & & & Mean & SD & Mean & SD & Mean & SD & Mean & SD \\
\hline & Month & \multicolumn{9}{|c|}{ Phase I } \\
\hline Baseline & April & 40 & $60.9^{\mathrm{ac}}$ & 24.4 & $6.4^{\mathrm{a}}$ & 3.3 & 5.1 & 2.8 & 941 & 533 \\
\hline Midway & June & 40 & $68.2^{\mathrm{a}}$ & 24.6 & $7.4^{\text {ad }}$ & 6.6 & 4.6 & 2.2 & 915 & 529 \\
\hline \multirow[t]{2}{*}{ Final } & August & 36 & $76.1^{\mathrm{b}}$ & 22.4 & $7.5^{\mathrm{b}}$ & 3.2 & 5.2 & 3.2 & 828 & 419 \\
\hline & & \multicolumn{5}{|c|}{$\mathrm{n}$} & \multicolumn{4}{|c|}{ Phase II } \\
\hline Baseline & October & 30 & $57.7^{\mathrm{c}}$ & 24.1 & $7.9^{\mathrm{bd}}$ & 3.2 & 5.0 & 2.8 & 834 & 379 \\
\hline Midway & December & 29 & $62.9^{\mathrm{ac}}$ & 30.7 & $10.4^{\text {cd }}$ & 4.6 & 4.8 & 3.3 & 899 & 458 \\
\hline Final & February & 28 & $61.3^{c}$ & 29.2 & $8.4^{b}$ & 3.7 & 5.2 & 3.0 & 920 & 593 \\
\hline
\end{tabular}

Means followed by different superscript lowercase letters, within columns, differ $(\mathrm{P}<.05)$, mixed model ANOVA, controlling for random effect of age and using Tukey-Kramer adjustment for multiple comparisons. Values were log transformed for statistical analyses, but are presented in original units.

${ }^{*}$ Minimal ultraviolet beta radiation in the fall to winter period.

25(OH)D: 25-hydroxyvitamin D; PTH: parathyroid hormone; OC: osteocalcin; CTX: C-terminal telopeptides of Type 1 collagen.

Table 4: Biomarkers of bone metabolism in elderly veterans living in long-term care facility (Mean \pm SD).
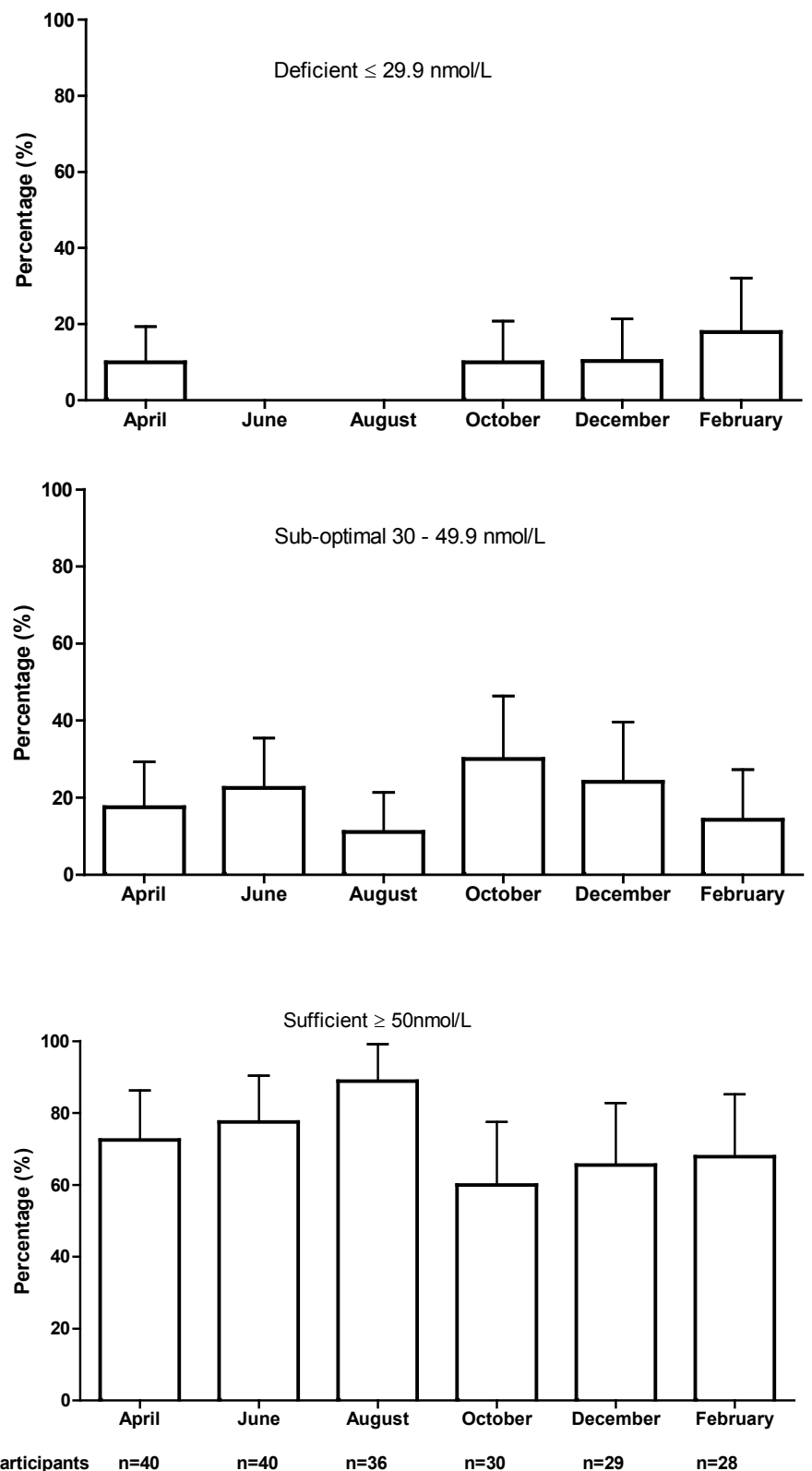

Figure 2: Proportion (\%, $\mathrm{Cl} 95 \%$ ) of participants according to $25(\mathrm{OH}) \mathrm{D}$ status during 1 year follow-up. 
indicative of secondary hyperparathyroidism. Although $25(\mathrm{OH}) \mathrm{D}$ and PTH concentrations fluctuated over time, CTX and OC did not show significant changes throughout this 1 year follow up study, reflecting a lack of change in bone turnover during the year.

In Phase I, PTH and OC demonstrated a positive correlation (Pearson $\mathrm{r}=0.32 ; \mathrm{p}=0.044$ ) only in April whereas $25(\mathrm{OH}) \mathrm{D}$ was negatively correlated to PTH (Pearson $\mathrm{r}=-0.398 \mathrm{p}=0.016$ ) in the month of August. Body mass index was correlated with $25(\mathrm{OH})$ $\mathrm{D}$ concentrations in April (Pearson $\mathrm{r}=-0.32 ; \mathrm{p}=0.019$ ). No other relationships were observed in this phase.

In the fall to winter period (Phase II), where $25(\mathrm{OH}) \mathrm{D}$ was at its minimal value, $25(\mathrm{OH}) \mathrm{D}$ was negatively correlated with $\mathrm{PTH}$ in October, December and February (Pearson $\mathrm{r}=-0.584$; $\mathrm{p}=0.001$, Pearson $\mathrm{r}=-0.519 ; \mathrm{p}=0.004$ and Pearson $\mathrm{r}=-0.440 ; \mathrm{p}=0.019$ respectively). CTX was positively correlated to $\mathrm{OC}$ at all 3 time points assessed in Phase II (Pearson $\mathrm{r}=0.546 ; \mathrm{p}=0.002$, Pearson $\mathrm{r}=0.523 ; \mathrm{p}=0.004$ and Pearson $r=0.636 ; p=0.001$, respectively). Correlations between $25(\mathrm{OH}) \mathrm{D}$ and biomarkers of bone health and function in February, when vitamin D status is dependent on exogenous sources, are presented in Figure 3. No other relationships were observed among bone biomarkers.

No correlations were seen between serum 25(OH)D concentration and handgrip strength, neither MMSE nor FEFA scores. However, the FEFA scores were negatively correlated to the handgrip strength (Pearson $\mathrm{r}=-0.43$; $\mathrm{p}=0.034$ ) in February demonstrating that handgrip strength is a reflection of functional mobility and the upper body strength is required for adequate daily activity.
Vitamin D intake in Phase II was positively correlated to energy intake, protein, calcium, phosphorus and potassium intakes $(\mathrm{p}<0.010)$, but was not correlated to $25(\mathrm{OH}) \mathrm{D}$ concentrations.

\section{Discussion}

This study was carried out in an elderly cohort of males living in a long-term care facility of Montreal (QC, Canada; $46^{\circ} \mathrm{N}$ ). Despite their advanced aged, the biological markers revealed a healthy population presenting with normal values for glucose, albumin, phosphate, total and ionized calcium as well as for total cholesterol and triglycerides. Participants maintained BMI, cognitive and functional status and number of medications taken over the year of study. The average serum concentrations of $25(\mathrm{OH}) \mathrm{D}$ were relatively good during the summer months in this elderly cohort when compared to the targets $(25(\mathrm{OH})$ $\mathrm{D}>50 \mathrm{nmol} / \mathrm{L}$ ) recently set by the IOM [5]. Only $34.5 \%$ and $32.1 \%$ were below $50 \mathrm{nmol} / \mathrm{L}$ of 25(OH)D in December and February when $25(\mathrm{OH}) \mathrm{D}$ is dependent on exogenous sources alone. These observations concur with other reports in nursing home facilities [10-12]. However, this report is the first to provide a yearly profile of $25(\mathrm{OH}) \mathrm{D}$ status in institutionalized elderly men over $80 \mathrm{y}$ as well as rigorous dietary assessment. Despite limited direct exposure to UVB, a small seasonal effect was observed in June and August where no participant presented $25(\mathrm{OH}) \mathrm{D}$ values below $30 \mathrm{nmol} / \mathrm{L}$ as observed in other studies of elderly $[7,9,12]$.

Although Canada's Food Guide (Health Canada) suggests that 400 $\mathrm{IU}(10 \mu \mathrm{g})$ of vitamin $\mathrm{D}$ be taken as a supplement by individuals $>50 \mathrm{y}$,

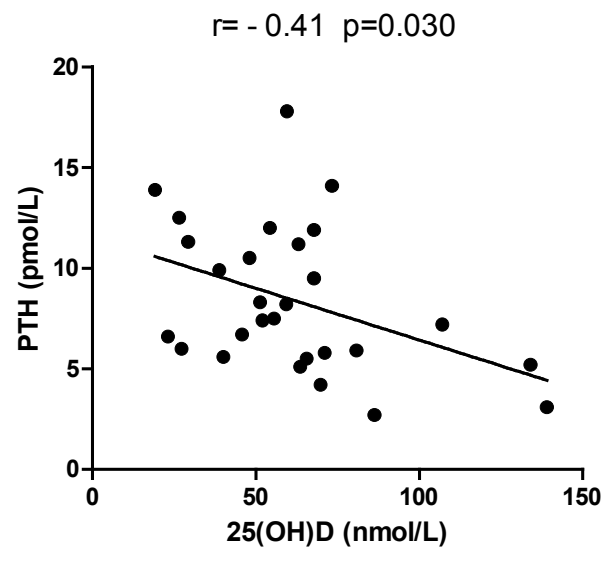

$r=0.13 p=0.523$

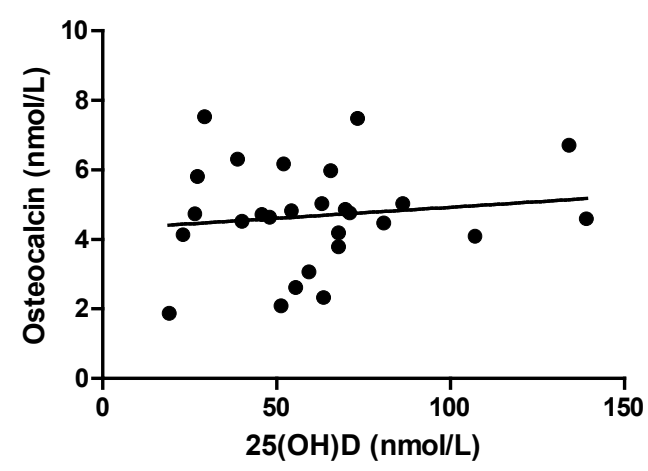

$r=0.20 p=0.323$

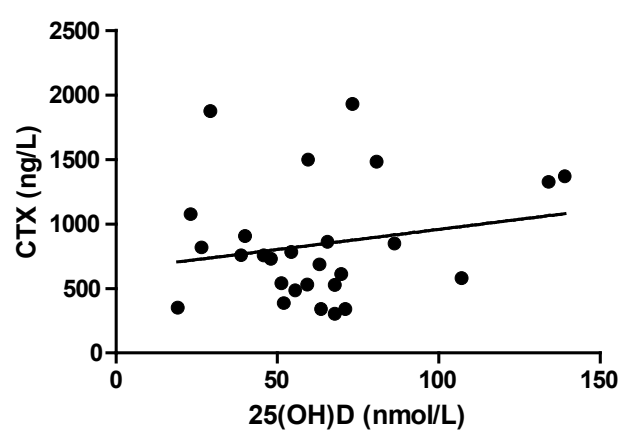

$r=0.30 p=0.124$

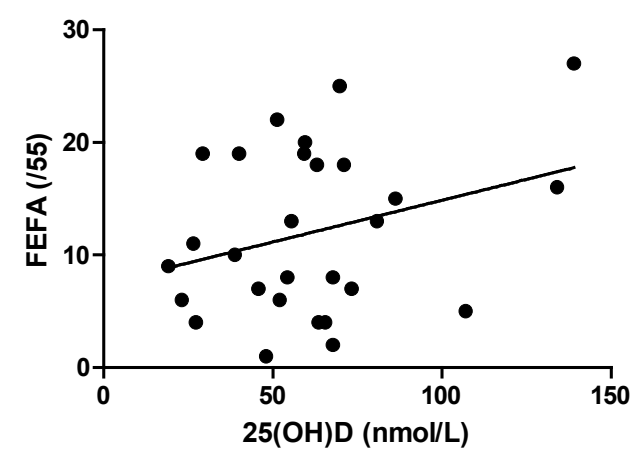

Values were log transformed for statistical analyses for $25(\mathrm{OH}) \mathrm{D}, \mathrm{PTH}, \mathrm{OC}$ and CTX, but are presented in original units.

Figure 3: Linear regression between $25(\mathrm{OH}) \mathrm{D}$ and PTH, OC, CTX and FEFA in February, when vitamin D status is dependent on exogenous sources. 
only $33 \%$ of participants were receiving supplements at the time of the study. Thus the majority of vitamin D intake was from diet. In Phase II, nutritional intake over time was stable and confirms the presence of a routine regarding food preferences. These results complement previous observations revealing low average intake of vitamin $D$ in the elderly living in a Canadian long-term care facility $[10,16,19,28]$, but provides new knowledge regarding food sources and status of vitamin $\mathrm{D}$ across a year. The main sources of vitamin $\mathrm{D}$ for this cohort were fortified milk, meal supplements and vitamin from tablets. Only one participant met the AI value of $600 \mathrm{IU}$, which prevailed at the time of the study, with food and meal supplements alone. With the new DRI values, 10 to $14 \%$ of participants reached the EAR with food and meal supplements. However, the actual intake from food was sufficient to meet the RDA for one participant in the month of December only.

The implications of not meeting recommended intakes of vitamin D extend beyond vitamin D status alone. In this study, PTH was elevated often throughout the course of the study but was only significantly elevated during the early winter segment of the study. As in the younger adult, PTH is known to increase with declining $25(\mathrm{OH})$ $\mathrm{D}$ status [29]. However, hyperparathyroidism is also associated with higher morbidity and mortality in the elderly $[26,27,30]$. OC and CTX did not significantly change over time in this group. This aligns with the modest changes in PTH and that the values were on average elevated for the majority of the year.

Other possible functional indicators of vitamin D status were explored in this study such as handgrip strength and function in daily living tasks. Contrary to previous observations in communitydwelling seniors with vitamin D deficiency, the FEFA [23] did not associate well with vitamin $\mathrm{D}$ intake or vitamin D status. It is possible that the $25(\mathrm{OH}) \mathrm{D}$ concentrations observed in our cohort were above a threshold for influencing functionality. Vitamin D status above 50 $\mathrm{nmol} / \mathrm{L}$ compared to lower status positively associates with physical performance, handgrip strength in community dwelling elderly [31] as well as with functional capacity [23]. However, it is negatively associated with frailty [32]. Dose response studies are required to clarify this association and determine if a threshold exists as related to optimal performance [5].

Although this study is a comprehensive look at vitamin D nutrition in elderly men living in a long-term care facility, the fact that it is entirely composed of elderly veterans and is of small sample size might hinder the extrapolation of our results to other elderly. It is also possible that participants ate more since they were aware that meal intake was documented, therefore increasing vitamin $\mathrm{D}$ intake. However, the similar BMI in both study phases and only $66 \%$ of vitamin D consumed suggests this was not the situation.

In summary, this study provided detailed data on food intake, vitamin $\mathrm{D}$ status and bone biomarkers for relatively healthy, well monitored, very old male veterans living in a long-term care facility over a year. This study underscores the importance of not only planning intakes to meet needs, but to observe actual food intakes since only $66 \%$ of the food was consumed. In this advanced aged population, vitamin $\mathrm{D}$ intake was positively correlated with vitamin D status during winter months. The main contributors of vitamin $\mathrm{D}$ in the diet of this longterm care facility were vitamin D fortified milk and meal supplements and tablet supplements. The newly published DRI values for vitamin $\mathrm{D}$ in the healthy population above $70 \mathrm{y}$ have changed from an $\mathrm{AI}$ value of $600 \mathrm{IU}(15 \mu \mathrm{g})$ to a EAR of $400 \mathrm{IU}(10 \mu \mathrm{g})$ and RDA of 800 IU $(20 \mu \mathrm{g})$ [5]. Reaching these recommendations with foods or meal supplements alone will be a challenge in the institutionalized elderly.
This study adds to the mounting evidence of insufficient intake of vitamin D by food and meal supplements alone as well as $25(\mathrm{OH}) \mathrm{D}$ concentration values below $30 \mathrm{nmol} / \mathrm{L}$ for up to $18 \%$ of this population in the winter months. Although vitamin D status was sufficient for a majority of participants, PTH was elevated and above the normal range in the fall and winter months suggesting that higher intakes could be beneficial. Future research should thus provide information including data on calcium and bone metabolism in elderly individuals living in long-term care facilities within higher vitamin $\mathrm{D}$ status ranges. Vitamin D dose-response studies in the elderly population should also provide information to reduce the knowledge gap in elderly males with regard to benefits of achieving vitamin $\mathrm{D}$ recommendations on health outcomes other than bone health.

\section{Acknowledgments}

This work was funded by the Canadian Foundation for Dietetic Research the Federation des producteurs doeufs de consummation du Québec and the Egg Farmers of Canada. Ms. Germain received Canadian Institutes for Health Research Clinician Scientist salary award and Dr. Weiler is a Canada Research Chair. All authors were involved in design, conduct and reporting of the study. The authors have no conflict of interest.

\section{References}

1. Annual Demographic Estimates: Canada, Provinces and Territories (2010) September, statistics Canada.

2. Holick MF (2006) High prevalence of vitamin D inadequacy and implications for health. Mayo Clin Proc 81: 353-373.

3. Hobbs F, Stoops N (2000) Demographic Trends in the 20th Century, Bureau of census, USA.

4. Bureau S (2012) Statistical Handbook of Japan, Japan

5. Ross AC, Taylor CL, Yaktine AL, Del Valle HB (2010) Dietary Reference Intakes for Calcium and Vitamin D. National Academies Press 482.

6. Barake R, Weiler H, Payette H, Donald KG (2010) Vitamin D status in healthy free-living elderly men and women living in Quebec, Canada. J Am Coll Nutr 29: $25-30$

7. Vecino VC, Gratton M, Kremer R, Manas RL, Duque G (2006) Seasonal Variance in Serum Levels of Vitamin D Determines a Compensatory Response by Parathyroid Hormone: Study in an Ambulatory Elderly Population in Quebec. Gerontology 52: 33-39.

8. Rucker D, Allan JA, Fick GH, Hanley DA (2002) Vitamin D insufficiency in a population of healthy western Canadians. CMAJ 166: 1517-1524.

9. Janz T, Pearson C (2013) Vitamin D blood levels of Canadians, Statistics Canada.

10. Adolphe JL, Whiting SJ, Dahl WJ (2009) Vitamin fortification of puréed foods for long-term care residents. Can J Diet Pract Res 70: 143-150.

11. Gloth FM 3rd, Gundberg CM, Hollis BW, Haddad JG Jr, Tobin JD (1995) Vitamin D deficiency in homebound elderly persons. JAMA 274: 1683-1686.

12. Liu BA, Gordon M, Labranche JM, Murray TM, Vieth R , et al. (1997) Seasonal prevalence of vitamin $D$ deficiency in institutionalized older adults. J Am Geriatr Soc 45: 598-603.

13. Orwoll E, Blank JB, Connor BE, Cauley J, Cummings S, et al. (2005) Design and baseline characteristics of the osteoporotic fractures in men (MrOS) study-a large observational study of the determinants of fracture in older men. Contemp Clin Trials 26: 569-585.

14. Langlois K, Finestone GL, Little J, Hidiroglou N, Whiting S (2010) Vitamin D status of Canadians as measured in the 2007 to 2009 Canadian Health Measures Survey. Health Rep 21: 47-55.

15. Tran B, Armstrong BK, Carlin JB, Ebeling PR, English DR, et al. (2012) Recruitment and results of a pilot trial of vitamin D supplementation in the general population of Australia. J Clin Endocrinol Metab 97: 4473-4480.

16. Lee LT, Drake WM, Kendler DL (2002) Intake of calcium and vitamin D in 3 Canadian long-term care facilities. J Am Diet Assoc 102: 244-247.

17. Germain I, Dufresne T, Donald GK (2006) A novel dysphagia diet improves the nutrient intake of institutionalized elders. J Am Diet Assoc 106: 1614-1623. 
Citation: Germain I, Agellon S, Weiler H (2013) Insufficient Vitamin D Intake and Low Vitamin D Status in Men Over 80 Y of Age: Intervention is Required To Meet Dietary Targets in Long-Term Care Facilities. Vitam Miner 2: 113.

18. Lengyel CO, Whiting SJ, Zello GA (2008) Nutrient inadequacies among elderly residents of long-term care facilities. Can J Diet Pract Res Summer 69: 82-88.

19. Hall KL, Denda CE, Morris M, Yeung H (2010) Dietary vitamin d intake among elderly residents in a veterans' centre. Can J Diet Pract Res 71: 49-52.

20. Thompson WA, Piche $L$ (2011) Nutritional analysis of a long-term care menu before and after an increase in the raw food cost allowance. Can J Diet Pract Res 72: 141-145

21. Ferrari BHA, Dietrich T, Orav EJ, Hu FB, Zhang Y, et al. (2004) Higher 25-hydroxyvitamin $\mathrm{D}$ concentrations are associated with better lower-extremity function in both active and inactive persons aged $>$ or $=60 \mathrm{y}$. Am J Clin Nutr 80: $752-758$

22. Lee HJ, Gong HS, Song CH, Lee JE, Lee YH, et al. (2013) Evaluation of vitamin $\mathrm{D}$ level and grip strength recovery in women with a distal radius fracture. $J$ Hand Surg Am 38: 519-525.

23. Gloth FM, Smith CE, Hollis BW, Tobin JD (1995) Functional improvement with vitamin $D$ replenishment in a cohort of frail, vitamin D-deficient older people. J Am Geriatr Soc 43: 1269-1271.

24. Scott D, Blizzard L, Fell J, Ding C, Winzenberg T, et al. (2010) A prospective study of the associations between 25-hydroxy-vitamin D, sarcopenia progression and physical activity in older adults. Clin Endocrinol (Oxf) 73: 581587.

25. Visser M, Deeg DJ, Puts MT, Seidell JC, Lips P (2006) Low serum concentrations of 25-hydroxyvitamin $\mathrm{D}$ in older persons and the risk of nursing home admission. Am J Clin Nutr 84: 616-622.

26. Bjorkman M, Sorva A, Tilvis R (2009) Parathyroid hormone as a mortality predictor in frail aged inpatients. Gerontology 55: 601-606.

27. Cawthon PM, Parimi N, Barrett-Connor E, Laughlin GA, Ensrud KE, et al. (2010) Serum 25-hydroxyvitamin D, parathyroid hormone, and mortality in older men. J Clin Endocrinol Metab 95: 4625-4634.

28. Hughes DB, Harris SS, Dallal GE (1997) Plasma calcidiol, season, and serum parathyroid hormone concentrations in healthy elderly men and women. Am J Clin Nutr 65: 67-71.

29. Fisher A, Goh S, Srikusalanukul W, Davis M (2009) Elevated serum PTH is independently associated with poor outcomes in older patients with hip fracture and vitamin D inadequacy. Calcif Tissue Int 85: 301-309.

30. Houston DK, Cesari M, Ferrucci L, Cherubini A, Maggio D, et al. (2007) Association between vitamin D status and physical performance: the InCHIANTI study. J Gerontol A Biol Sci Med Sci 62: 440-446.

31. Shardell M, Hicks GE, Miller RR, Kritchevsky S, Andersen D, et al. (2009) Association of low vitamin $D$ levels with the frailty syndrome in men and women. J Gerontol A Biol Sci Med Sci 64: 69-75.

32. Johnson MA, Davey A, Park S, Hausman DB, Poon LW (2008) Age, race and season predict vitamin $D$ status in African American and white octogenarians and centenarians. J Nutr Health Aging 12: 690-695. 